\title{
Percepções de um grupo de licenciandos em Ciências Biológicas acerca da observação e do registro da observação na investigação científica a partir de uma sequência didática
}

\section{Preservice science teachers' perceptions of scientific observation and observation record developed by a teaching unit}

\author{
Karlla Vieira do Carmo ${ }^{1}$. Louise Brandes Moura Ferreira ${ }^{2}$. \\ Carla Medeiros y Araujo ${ }^{3}$
}

\begin{abstract}
Resumo: A observação e o registro científicos são habilidades e procedimentos centrais para compreender a Ciência. Entretanto, há carência de materiais para seu ensino no currículo de licenciandos em Ciências Biológicas no Brasil. Esta pesquisa descreve as percepções de um grupo de graduandos de uma Licenciatura em Ciências Biológicas sobre a observação e o registro científicos ao longo do desenvolvimento de uma unidade didática. Dados qualitativos foram coletados por meio de entrevistas semiestruturadas, questionários, fotografias, artefatos da produção discente, áudio e videotapes de atividades em sala de aula. Constatou-se o refinamento das percepções dos estudantes acerca dessas habilidades, caracterizando-as como subjetivas, detalhadas, influenciadas pelos conhecimentos prévios e técnicos do observador assim como por instrumentos. Essas características vão ao encontro dos trabalhos de epistemólogos que definem as observações e os registros como dependentes da formação teórica e prática do cientista que interpreta os fenômenos com base em teorias vigentes.
\end{abstract}

Palavras-chave: Ensino superior. Ensino de biologia. Investigação científica. Observação.

\begin{abstract}
Scientific observation and observation records are central science process skills to the understanding in science. Nevertheless, there is a lack of curriculum materials developed to teach these skills to science teachers in training at the undergraduate level in Brazil. This study reports the perceptions of a group of preservice biology teachers regarding the scientific processes of observation and observational recording during a teaching unit. The study's authors collected qualitative data through semi-structured student interviews, questionnaires, photographs, assignments, and videotaping/audiotaping of class activities. The study's findings show that students refined their perceptions of observation and recording processes during the teaching unit, labeling them as subjective, detailed, influenced by the observer's previous knowledge, and by instruments. These characteristics corroborate an epistemological perspective in that observation and observational records are defined as dependent on the theoretical background and practical training of a scientist who also interprets phenomena according to a historically situated theory.
\end{abstract}

Keywords: Undergraduate teaching. Biology teaching. Scientific research. Observation.

\footnotetext{
${ }^{1}$ Universidade Federal de Goiás (UFG), Departamento de Ciências Biológicas, Catalão, GO, Brasil. E-mail:

$<$ karlla.carmo@gmail.com>.

${ }^{2}$ Universidade de Brasília (UnB), Faculdade de Planaltina, Planaltina, DF, Brasil.

${ }^{3}$ Universidade de Brasília (UnB), Departamento de Genética e Morfologia, Brasília, DF, Brasil.
} 


\section{Habilidades e procedimentos da investigação científica}

Na prática da ciência, os cientistas cotidianamente engajam-se em atividades tais como a observação dos fenômenos e o registro dessas observações (DASTON; LUNBECK, 2011). A observação e a comunicação, entre outros, são habilidades e procedimentos da investigação científica $^{4}$ que podem ser concebidos como um conjunto de habilidades presentes nas investigações das mais variadas áreas da ciência (PADILLA, 1990). A comunicação é um termo amplo que abrange tanto os registros observacionais iniciais e idiossincráticos que acontecem durante a pesquisa, como o texto final publicado contendo os resultados da investigação (HOLMES; RENN; RHEINBERGER, 2003). Neste trabalho, comunicar o observado significa registrar a observação por meio da escrita, de desenhos e esquemas.

As habilidades e procedimentos da investigação científica foram classificados para fins de ensino como básicos e integrados. Os básicos são a observação, a comunicação, a classificação, a mensuração, a inferência e a predição. Os integrados são a identificação e o controle de variáveis, a elaboração de definições operacionais, a construção de hipóteses, a interpretação de dados, a experimentação e o uso de modelos (AMERICAN ASSOCIATION FOR THE ADVANCEMENT OF SCIENCE, 1965).

Ao analisarem a relação entre a prática científica e o ensino de ciências naturais no nível superior, Coil et al. (2010) propõem um currículo com atividades nas quais os discentes possam aprender e exercitar as habilidades e os procedimentos da investigação científica de maneira análoga à dos cientistas. Somente dessa forma, de acordo com eles, os estudantes se tornariam capazes de atingir proficiência e se preparariam melhor para carreiras científicas. Harlen (1999, 2002) argumenta que nenhuma educação científica é completa quando as aulas de ciências só enfatizam o conteúdo e deixam de fornecer subsídios para que os alunos sejam capazes de raciocinar cientificamente, usando as habilidades e os procedimentos da investigação científica. Além disso, para a pesquisadora, o raciocínio científico ajuda os aprendizes na compreensão do mundo à sua volta. Se em uma investigação, por exemplo, os discentes não forem capazes de notar evidências que neguem a hipótese inicial da pesquisa, então "os conceitos que daí emergem não os ajudarão a compreender o mundo" (HARLEN, 1999, p. 130). Nesse sentido, ensinar as habilidades e os procedimentos da investigação científica é algo de fundamental importância na formação dos educandos, quer venham a se tornar cientistas ou não. Tal aprendizagem poderá também auxiliar os alunos na compreensão e melhor entendimento de como os cientistas obtém os conhecimentos sobre o mundo ao seu redor (HANUSCIN; ROGERS, 2008).

Apesar da necessidade do ensino das habilidades da investigação e dos procedimentos da investigação científica tal como desenvolvido acima, poucas pesquisas abordaram as percepções dos alunos e professores acerca da observação e do registro da observação. O que se nota é uma quantidade razoável de relatos de experiência e roteiros para o ensino de tais habilidades, auxiliando os professores a implementarem atividades escolares normalmente em consonância

\footnotetext{
${ }^{4}$ A expressão "habilidades e procedimentos da investigação científica" é uma tradução livre do inglês science process skills. 
Percepções de um grupo de licenciandos em Ciências Biológicas ...

com as políticas públicas educacionais adotadas pelo país de origem. No caso brasileiro, tanto a abordagem investigativa como a de construção de guias didáticos auxiliares à práxis docente ainda se revelam campos abertos a explorar quando se trata do ensino da observação e do registro da observação.

Neste artigo relatamos os resultados de uma pesquisa qualitativa do tipo professor-pesquisador sobre as percepções de um grupo de licenciandos em Ciências Biológicas acerca dos procedimentos da observação e do registro da observação. A pesquisa se deu num contexto maior (CARMO, 2012) envolvendo o ensino da Biologia Celular e Molecular bem como o procedimento da inferência.

\section{Observação e registro da observação}

A observação é fundamental na prática científica das ciências empíricas (DASTON, 2008). Ela é realizada por meio dos cinco sentidos e instrumentos que os potencializam em situações naturais ou experimentais. Daston (2008) nota que apesar dessa centralidade na prática científica a observação foi negligenciada como um objeto de investigação por filósofos, historiadores e cientistas até a segunda metade do século XX. Sua "invisibilidade" (DASTON, 2008, p. 97), argumenta a autora, pode se dar ao fato de a observação ter sido considerada como algo tão básico a ponto de não ter merecido nenhuma atenção desses pesquisadores. Uma exceção foi o trabalho do médico e epidemiologista polonês Ludwik Fleck (1986a, 1986b, 2010) ao afirmar que a habilidade de observar cientificamente requer treinamento e vasta experiência na área. Segundo ele, a observação do novato diverge da observação do especialista apesar de "enxergarem" o mesmo objeto ou fenômeno. Em outras palavras, leigos vêem apenas borrões e bolhas ao microscópio de luz, histologistas identificam tecidos; leigos escutam somente o canto de determinada ave, ornitólogos especialistas naquela espécie são capazes de saber se o canto é de acasalamento ou não. Isso se dá porque, segundo Fleck, a boa observação depende necessariamente do domínio do observador numa determinada área do conhecimento científico. Ele afirma que: “[...] para enxergar é necessário saber o que é essencial daquilo que não é [...] saber qual é a categoria que o objeto pertence. De outra forma, nós vemos mas não enxergamos, olhamos atentamente para muitos detalhes do que é observado sem compreender sua completude" (FLECK, 1986b, p. 130).

De acordo com Fleck (1986a), tem-se por consequência que a habilidade de observar não é algo generalista e não inclui todos os campos da ciência ao mesmo tempo. Para tornar-se proficiente no observar é necessário que o aprendiz adquira uma certa "aptidão mental" (FLECK, 1986a, p. 61) para enxergar determinados fenômenos da natureza. A aptidão para observar numa dada área é o resultado da educação teórica e prática de um determinado indivíduo.

Na Filosofia da Ciência, Hanson $(1965,1975)$ assevera que toda observação científica é feita tendo como pano de fundo uma teoria. Segundo Hanson (1965, p. 19), "a observação de x é formada pelo conhecimento prévio de x", ou seja, o especialista interpreta um fenômeno com base em uma teoria. Para ele, apesar de podermos separar conceitualmente o registro da observação do fenômeno observado, eles são como "matéria e forma", "urdidura e tecido", "pintura e tela" (HANSON, 1975, p. 127) assim, "separar matéria e forma numa estátua torna-a ininteligível... separar os sinais-de-apreensão-de-sensações da apreciação-do-significado dêsses sinais destruiria o que entendemos por observação científica" (HANSON, 1975, p. 128, grifo do 
autor). Thomas Kuhn (1998), em sua célebre obra A estrutura das revoluções científicas afirma que os praticantes de uma determinada comunidade científica e época enxergam os fenômenos de acordo com paradigmas. Um paradigma proporciona uma certa visão de mundo e modelos derivados dessa visão para a resolução de problemas ou "quebra-cabeças" (KUHN, 1998).

$\mathrm{Na}$ formação de professores de Ciências, Gil Pérez et al. (2001) chamam atenção para a ausência dessas visões epistemológicas nos currículos. Para eles essa é uma "deformação" que precisa ser corrigida dado que os currículos veiculam a ideia de que a observação é uma atividade "neutra". Os pesquisadores dão a essa visão equivocada o nome de "concepção empírico-indutivista e ateórica” do trabalho científico (GIL PÉREZ et al., 2001, p. 129).

A observação deve ser acompanhada pelo registro da observação. Os registros são formas de documentar o observado e de dar suporte às análises científicas. Ramón y Cajal (2005, p. 118, tradução nossa) afirma que nas ciências biológicas como a Anatomia a "boa observação" deverá ocorrer paralelamente ao desenho, pois "o ato de desenhar disciplina e fortalece a atenção, obriga que se explore a totalidade do fenômeno estudado e evita, dessa maneira, que escapem detalhes frequentemente despercebidos na observação comum." Enfatiza a necessidade do conhecimento especializado, condições de estudo adequadas e completo domínio da técnica na preparação de espécimes. Deve-se também “evitar toda a pressa na apreciação dos fatos” (RAMÓN Y CAJAL, 2005, p. 118, tradução nossa) e repetir o ato de registrar quantas vezes for necessário para que se obtenha um desenho que evidencie todas as nuances do objeto estudado. Em outras palavras, tempo para a observação e registro são condições centrais para a excelência no desenho científico. Como derivado das afirmações de Ramón y Cajal, o desenho do neófito na área será bastante diferente do especialista. Portanto, na Anatomia, não só a "boa observação" necessita que o observador seja adequadamente educado e treinado no domínio daquele conhecimento, as mesmas qualidades são exigidas para que se obtenha dele o "bom desenho".

Um anatomista pode executar uma série de desenhos de um determinado órgão e ressaltar, à medida que observa, características pertinentes ao seu estudo. Pode também rabiscar esquemas e modelos de processos associados, fazer afirmações e formular perguntas. Latour e Woolgar (1997) dão o nome de "inscrições" a essas formas escritas de representação do fenômeno observado. As inscrições são realizadas durante a investigação e servem tanto para documentar o fenômeno como para embasar a argumentação científica do texto a ser publicado. Do processo ao produto final - a comunicação científica com os pares - as inscrições refinamse e normalizam-se com a finalidade de se adequar ao conhecimento consensual científico de uma determinada comunidade de especialistas. A normalização, ou a redução das inscrições aos padrões científicos é o que propicia uma linguagem comum aos cientistas e a certeza de que estão tratando dos mesmos fenômenos. Bons registros também têm a função de preservar as observações realizadas para serem posteriormente consultadas (NORRIS, 1984).

\section{O Ensino da Observação e do Registro da Observação}

As habilidades e os procedimentos da investigação científica são processos conectados e nem sempre é possível estabelecer uma diferenciação precisa entre eles. Por exemplo, algumas observações são inerentemente inferenciais e, portanto, já interpretativas. Entretanto, 
pesquisadores na área de ensino de Ciências acreditam que é possível ensinar a observação e o registro da observação, o pensar reflexivo sobre essas habilidades e orientar os professores de ciências para as melhores práticas.

Pesquisadores como Lawson (2009) sugerem que atividades de meta-reflexão sejam realizadas em adição aos procedimentos e habilidades da investigação científica nas aulas de ciências. Isso requer, entretanto, que o professor seja capaz de ajudar os alunos e estruturar lições que os façam refletir sobre o próprio pensamento (DRIVER, 1985). Por exemplo, que os aprendizes sejam levados a interromper o fluxo cognitivo e se perguntem ao observar, "estou realmente desenhando o que vejo?" Norris (1984, p. 135, tradução nossa) elabora uma lista de critérios para a boa observação com itens que incluem "ser hábil na observação da coisa observada e na técnica utilizada", "ter tempo suficiente para a observação", "ter conhecimento teórico do fenômeno observado" e "equipamentos em pleno funcionamento". Para o bom registro da observação, ele enfatiza a necessidade de fazê-lo "de forma a não extrapolar o que pode ser justificado pela técnica observacional utilizada” (NORRIS, 1984, p. 136, tradução nossa). Para Norris, esses critérios deveriam orientar os elaboradores de currículos bem como professores ao lidar com atividades observacionais em ciências.

Além dos critérios elencados por Norris (1984), salientam-se as diferenças biológicas existentes entre distintos observadores, isto é, o fato de os órgãos dos sentidos apresentarem variações individuais, não respondendo de maneira igualitária quando diferentes indivíduos observam os mesmos objetos ou fenômenos, o mesmo ocorrendo com suas interpretações (STANSFIELD, 2012), mesmo considerando a interface instrumental que amplia nossos sentidos e nos permitem "ver" o que antes "não víamos". O autor ressalta que essa percepção sensorial varia entre os indivíduos e ao longo da vida de um mesmo indivíduo, modificando-se em decorrência do nosso processo de envelhecimento biológico. Também expõe que tomar ciência das limitações de nosso sistema sensorial e da natureza subjetiva de muitos dados empíricos pode servir como estímulo à reflexão, ao senso crítico e à consideração de distintas opiniões por parte dos alunos ao desenvolverem atividades de aprendizagem de investigação científica.

Na pesquisa empírica existe uma quantidade razoável de roteiros didáticos que incluem o ensino da observação e do registro da observação (ANDERSON; MARTIN; FASZEWSKI, 2006; CHECKOVICH; STERLING, 2001; KLENTSCHY, 2010) bem como relatos de experiências didáticas (ASHBROOK, 2010; GOSTEV; WEISS, 2007). Esses trabalhos foram realizados com crianças em idades escolares variadas.

Smith e Reiser (2005) desenvolveram para estudantes do ensino médio o que denominam "modelo de investigação" para auxiliar a aprendizagem de diversas habilidades da investigação científica por alunos dos Estados Unidos. Nesse modelo, os autores enfatizam a relação da observação com a articulação da teoria pautada por Thomas Kuhn, no intuito dos alunos compreenderem que as observações científicas podem ser utilizadas para gerar novas hipóteses e articular teorias científicas. Outra pesquisa relacionada às percepções dos alunos acerca da observação foi desenvolvida por Haslam e Gunstone (1996) em uma escola pública australiana. De forma geral, os alunos relataram que a observação auxiliava na aprendizagem e na obtenção de conhecimento científico, mesmo considerando-a como um processo direcionado pelo professor. Muitas vezes já anteviam, sabiam ou tinham sido alertados pelo docente sobre o resultado do experimento em curso, o que diminuiu, segundo eles, o interesse em acompanhar o processo. O envolvimento dos alunos nas atividades observacionais também foi dependente da 
área de conhecimento e do tipo e duração do experimento. Por exemplo, atividades dinâmicas e rápidas como determinadas reações químicas foram consideradas mais interessantes do que as dissecções anatômicas de animais que requeriam tempo mais prolongado de observação. $\mathrm{O}$ tamanho dos grupos de trabalho nas aulas laboratoriais também foi acentuado como determinante no engajamento dos alunos no processo, com preferência para os trabalhos em duplas que implicaram em participação de todos os integrantes na atividade escolar. Haslam e Gunstone (1998) notaram que a atuação diferenciada de cada docente em sala de aula influenciou diretamente a compreensão da classe quanto ao procedimento de observação.

No âmbito do ensino superior, tendo como público-alvo um grupo de licenciandos em Ciências Biológicas de uma universidade pública turca, Oğuz-Ünver e Yürümezoğlu (2009) elaboraram e aplicaram atividades com questões direcionadas que tinham como objetivo incentivar a compreensão dos participantes sobre o caráter empírico da observação (o uso dos sentidos e de instrumentos), a importância da observação no contexto da investigação científica e sua relação com outras habilidades, como o registro. Os autores acentuam a necessidade da aplicação de estratégias para o ensino e a aprendizagem da observação, apresentando ponto de vista em sintonia ao de Driver (1985), isto é, de que os estudantes precisam de perguntas bem formuladas para guiá-los em exercícios de observações científicas. Os autores consideram que o ensino da observação científica é tão relevante quanto o dos métodos experimentais nas aulas de ciências, e deve ocorrer por meio de um sistemático acompanhamento do professor que organiza as atividades observacionais, elabora questionamentos que estimulam a observação e promove discussões com os discentes acerca do material observado.

Ahtee et al. (2009) coletaram as percepções de futuros professores do ensino primário na Finlândia sobre a observação científica. De forma geral, os estudantes relacionaram prioritariamente o procedimento de observar com o de "notar as coisas" ao redor, não demonstrando conhecimento sobre o papel central da observação na investigação científica. A reflexão e a inferência não foram vinculadas à observação, assim como o uso de equipamentos (como microscópios e telescópios) praticamente não foi citado como meios para ampliar os sentidos durante o processo de observação. Os estudantes acentuaram o conhecimento prévio, a experiência, a motivação, o interesse e a empatia como relevantes para manter a atenção e a concentração no ato de observação. Após a análise dessas percepções, os autores enfatizaram que a observação científica é um processo complexo e que deve ser ensinado também para licenciandos. Verifica-se que mesmo em estudantes altamente selecionados para o exercício da docência em escolas de ensino primário, como o são o da Finlândia, há essa demanda no processo de formação profissional.

\section{Materiais e métodos}

\section{Pergunta da pesquisa, instrumentos de coleta de dados, características do local de coleta dos dados e dos participantes}

A pergunta desta pesquisa foi: quais as percepções de um grupo formado por seis licenciandos em Ciências Biológicas sobre a observação e o registro da observação a partir de atividades didáticas em uma unidade de ensino que oportunizassem reflexões sobre as duas 
habilidades? Dada a natureza qualitativa desta investigação (BOGDAN; BIKLEN, 1994), os instrumentos de coleta de dados usados foram questionários, entrevistas semiestruturadas, filmagens das aulas, fotografias, gravações em áudio e materiais diversos da produção discente.

A pesquisa ${ }^{5}$ realizou-se em um campus de uma Universidade Federal que conta com um total de 2.025 estudantes, localizada em uma próspera cidade de pequeno porte da região Centro-Oeste do Brasil. A unidade de ensino desenvolveu-se no segundo semestre de 2011, na disciplina Ensino de Ciências e Biologia que faz parte do rol de obrigatórias do quarto período da Licenciatura em Ciências Biológicas. A turma era composta por 21 alunos, sendo dois do sexo masculino e 19 do sexo feminino, com faixa etária variando entre 19 e 20 anos. Os alunos tinham semanalmente cinco horas/aulas consecutivas, com intervalo de 20 minutos (três horas/aulas com intervalo e mais duas horas/aulas), totalizando uma carga horária de 96 horas.

O rendimento acadêmico dos alunos na disciplina foi o critério utilizado para a análise dos dados. Dos 21 estudantes aprovados, 6 (seis) foram selecionados para compor a amostra pesquisada. A formação dessa amostra se deu em decorrência da necessidade de reduzir a quantidade de dados coletados para que a análise fosse factível (PATTON, 2002). Os seguintes passos foram utilizados para a formação da amostra: (1) os alunos deveriam ter participado integralmente das atividades da unidade de ensino; (2) 3 (três) grupos foram formados de acordo com a variedade das menções dos estudantes (grupo dos alunos com menção média, grupo com menção média-superior e grupo com menção superior), e (3) 2 (dois) alunos foram escolhidos em cada grupo pelo fato de terem as notas mais próximas à média de cada intervalo (Dayane ${ }^{6}$ e Laura para o grupo com menção média, Isaura e Gisela para o grupo com menção média-superior e Isadora e Rian para o grupo com menção superior).

Por fim, verificou-se que todos os 6 (seis) alunos que compuseram a amostra haviam cursado e tinham sido aprovados nas disciplinas Biologia Celular e Molecular e Biologia dos Tecidos, sendo que dois deles (Isadora e Rian) foram monitores por um ano da última disciplina. Essa característica da amostra foi algo espontâneo, dado que as disciplinas não eram pré-requisitos de Ensino de Ciências e Biologia, onde a unidade de ensino e coleta tiveram lugar.

\section{Atividades didáticas executadas para coleta de dados}

Reportaremos 11 atividades pertencentes a uma sequência de seis aulas composta por um total de 26 atividades e uma entrevista semiestruturada. As atividades relatadas a seguir nos permitiram colher dados acerca da percepção dos alunos sobre as habilidades e procedimentos da observação e do registro da observação e estão numeradas de acordo com a unidade didática completa (ver CARMO, 2012). O restante das atividades da sequência didática incluiu a habilidade e o procedimento da inferência, tópico não abordado neste artigo.

\footnotetext{
${ }^{5}$ A pesquisa seguiu os ditames da Resolução do Conselho Nacional de Saúde 196/96 (BRASIL, 1996), vigentes na época da coleta de dados, que trata dos cuidados éticos em pesquisas com seres humanos e foi aprovada por um comitê de ética e pesquisa institucional.

${ }^{6}$ De acordo com as normas para pesquisas com seres humanos (ver nota anterior), os nomes dos alunos foram substituídos por pseudônimos.
} 
Como Atividade 1 foi aplicado um questionário de sondagem sobre os conhecimentos dos alunos acerca das habilidades e procedimentos da investigação científica e sua relevância no ensino de Biologia Celular e Molecular. A pergunta do questionário, entre outras, com resultados e discussão explicitados neste trabalho foi a seguinte: o que você entende por observação, registro e inferência?

$\mathrm{Na}$ mesma aula, transcorreu a realização de mais duas atividades (Atividades 2 e 3 ) no intuito de introduzir a discussão da observação tanto no cotidiano como na Ciência e compreender o caráter subjetivo e a influência dos conhecimentos prévios na observação. Foram utilizados dados de papelão com imagens em quatro das seis faces, primeiramente com imagens de pessoas comuns e, posteriormente, com imagens diversificadas de células. Independentemente da natureza da imagem observada, procedeu-se do seguinte modo: toda a turma formou um círculo na sala de aula, com o dado no centro, resultando na visualização de apenas duas imagens ao mesmo tempo por parte de cada aluno que permanecia sentado. Os alunos registraram suas observações e as reportaram aos colegas para que fizessem uma representação mental das imagens. Depois de cada explanação, o dado foi virado para que os discentes pudessem observar as imagens descritas por seus colegas. As semelhanças e divergências das imagens reais com as imagens idealizadas foram debatidas.

Após leitura prévia (Atividade 4) foi concretizada a discussão (Atividade 5) do texto "Habilidades fundamentais na ciência: a observação" (HAURY, 2002) com a finalidade de incentivar a compreensão do caráter subjetivo e a influência dos conhecimentos prévios na observação. O texto traduzido foi acompanhado de um roteiro de reflexão de leitura com perguntas que acentuaram os principais tópicos abordados pelo autor, quais sejam: o papel da observação na ciência e a importância de se enfatizar as habilidades e procedimentos da investigação científica no ensino de ciências.

As atividades subsequentes (Atividades 6 a 9) estavam centradas no uso do microscópio de luz com o objetivo de observar e registrar o observado, bem como possibilitar a reflexão acerca da influência do instrumental na observação, no caso, do microscópio de luz. Nas Atividades 6 e 7, relembrou-se a estrutura física e funcionamento do microscópio de luz, prosseguindo para atividade adaptada de Message et al. (1988) e Dessen e Oyakawa (2011) que trata da observação e desenho de pedaços de papeis nos quais foram impressas letras minúsculas (a, g, f, h, r, t) com visualizações "a olho nu" e ao microscópio, tendo como objetivo a percepção da inversão da imagem proporcionada pelo equipamento.

Em outra aula, foi aplicado um questionário (Atividade 11) para conhecer as percepções sobre a observação e o registro da observação, por meio das seguintes perguntas: (1) o que você aprendeu sobre a observação e o registro da observação nas últimas aulas?; (2) as atividades do último encontro o(a) fizeram ficar pensando sobre alguma coisa? Em caso afirmativo, escreva explicitando sua ideia.

A Atividade 13 envolveu o uso do microscópio de luz para a visualização de cortes histológicos de fígado com o objetivo de refinar a diferença entre a observação e o registro da observação. Os alunos foram incentivados, por meio de roteiro de atividade, a observar os cortes histológicos, executar desenhos (registros) de estruturas celulares específicas (citoplasmas, núcleos e nucléolos de hepatócitos) e refletir sobre os registros efetuados.

A entrevista semiestruturada individual foi realizada após a finalização da sequência didática, isto é, ao término das 26 atividades e elencou uma série de perguntas no intuito de 
Percepções de um grupo de licenciandos em Ciências Biológicas ...

coletar dados acerca das percepções dos alunos. Entre as perguntas efetuadas, cada aluno foi questionado se a sequência didática aplicada possibilitou reflexão acerca da observação e sobre as características do registro da observação e suas peculiaridades.

\section{Resultados e discussão}

Por meio do questionário de sondagem, nenhum dos discentes soube conceituar observação para além do senso comum. Sobre o registro da observação todos os licenciandos o relacionaram com o ato de observar. Laura afirma "é um registro do ato observado, passando para o papel, tirando foto, filmagem ou algo assim." Esse resultado vai ao encontro do que foi verificado por Ahtee et al. (2009) após aplicar questionários com licenciandos da Finlândia que também não revelaram conhecimento sobre o tema tão além do senso comum.

$\mathrm{Na}$ atividade com dados contendo imagens de pessoas comuns, as observações e os registros das observações divergiram no grupo. Incentivados a discutir, os estudantes concluíram que os registros feitos relatavam observações influenciadas pela subjetividade do observador, bem como seus conhecimentos prévios. Já nesse primeiro momento, os estudantes iniciaram a compreensão de que, portanto, sendo o registro uma consequência da observação, será ele também subjetivo e impregnado pela experiência e pelos conhecimentos prévios do observador, pois as observações não são cópias da realidade (FLECK, 1986b; HANSON, 1965, 1975; KUHN, 1998). Mais adiante, estenderemos a discussão desses pontos que foram novamente externados pelos alunos na fase final de coleta de dados, isto é, na entrevista semiestruturada.

Como resultado da atividade subsequente, a do dado contendo imagens de células, a maioria dos alunos registrou apenas a observação de uma das quatro imagens disponibilizadas. Acentua-se que em virtude da disposição das carteiras, era possível para cada aluno observar até duas faces do dado em cada ciclo de observação. O registro da observação de somente uma das imagens pode estar relacionado ao pré-requisito dos estudantes, ou seja, eles tomaram notas possivelmente apenas daquelas imagens que reconheceram. Dentre os alunos, ficou evidenciado que dois deles possuíam mais conhecimentos prévios de Biologia Celular e Molecular, justamente aqueles que foram monitores da disciplina Biologia dos Tecidos. Isadora registra "São várias células delimitadas pela membrana, cada qual com seu núcleo esférico" e Rian anota "Vejo células justapostas, algumas polinucleadas, com formatos retangulares e algumas com formato meio quadriculado". Uma terceira aluna registrou a observação de duas imagens, contudo não as relacionou com células, acentuando a semelhança das imagens com "obras de arte". A distinção entre os registros dos alunos vai ao encontro da ideia de Fleck (1986a, p. 61) de que a proficiência do observador é atingida a partir de uma certa "aptidão mental", adquirida a partir de educação teórica e prática do indivíduo. Infere-se que a vivência mais prolongada de Isadora e Rian com os temas celulares, ao longo de seus trabalhos de monitoria, tenha permitido o alcance de uma "aptidão" que os outros alunos não atingiram como participantes da disciplina de graduação Biologia dos Tecidos.

$\mathrm{Na}$ sequência das atividades, os alunos leram e discutiram o texto Habilidades fundamentais na ciência: a observação (HAURY, 2002). No debate, os alunos usaram de maneira correta os conceitos e termos introduzidos pelo texto, podendo ser interpretado como uma continuidade da apropriação conceitual. Os estudantes, aparentemente, evidenciaram um entendimento sobre o que é observação incluindo novamente os conhecimentos pré-existentes como agentes 
influenciadores. Gisela afirma: "A observação é influenciada por conhecimentos... olhar não é observar". A aluna Isadora relacionou o desenvolvimento da habilidade de observação à construção do fazer científico:

$O$ aluno dependendo da maturidade deve ser capaz de manipular instrumentos que aprimorem a capacidade de observação como por exemplo, uso do microscópio, lupa, termômetro...enfatizar essa habilidade é importante para ensinar como se constrói o saber cientifico.

Esses comentários apresentam nítida influência do texto utilizado para o debate e corroboram o trabalho de Padilla (1990) que enfatiza que as habilidades e procedimentos da investigação científica são passíveis de serem ensinadas e que refletem o comportamento dos cientistas. Porém, as afirmações dos alunos nesta etapa do trabalho afloraram a partir de pauta explícita de Haury (2002), não se podendo caracterizá-las exatamente como percepções, correndo-se o risco de terem sido apenas reproduções dos pontos de vista defendidos pelo autor.

Depois da leitura e discussão do texto, tiveram lugar as atividades de uso de microscópio de luz. Os licenciandos ficaram extremamente surpresos com a observação da inversão da imagem, com um dos alunos destacando a necessidade de conhecer o funcionamento do instrumental, referindo-se especificamente "a forma com que o aparelho processa o objeto" (Rian). Essa percepção vai ao encontro do acentuado por Klentschy (2010) quando conceitua a observação na ciência englobando competências relacionadas à coleta de dados por meio dos sentidos, assim como de instrumentos que possibilitam ir além desses sentidos. Mas, a afirmativa do aluno Rian é mais abrangente, pois há a compreensão de que o microscópio interfere na imagem. Para além da ampliação dos sentidos, não se encontra facilmente na literatura em ensino de ciências discussões acerca da interferência do instrumental e da metodologia empregada para a observação e o registro da observação na investigação científica. Percebe-se um sistemático enaltecimento acerca do desenvolvimento da tecnologia para proporcionar maior acuidade na práxis científica, sem considerar as modificações que o fenômeno ou objeto a serem observados possam ser alvos, dependendo da técnica e/ou instrumental utilizados.

Por meio do questionário após a execução das primeiras atividades da unidade didática, uma aluna se referiu à necessidade de prestar atenção aos detalhes do objeto no momento da observação. Laura: "Observação é algo que tem que ser realizado com bastante atenção, detalhadamente." A discussão desse tópico dar-se-á na análise dos dados da entrevista semiestruturada, em função da extrapolação dessa percepção para o registro.

O questionário também revelou a ênfase dada pelos alunos quanto à necessidade de conhecer o objeto de estudo para poder realizar observações mais acuradas. "Para a observação ser mais clara a pessoa tem que entender um pouco sobre o que está observando" afirmou Laura, nitidamente desenvolvendo a percepção sobre a relação direta da qualidade da observação com os conhecimentos prévios e técnicos de quem observa (FLECK, 1986a).

No que tange o registro da observação, os estudantes também afirmaram ser esse procedimento influenciado por conhecimentos prévios e, portanto, subjetivo, preocupando-se com a comunicação científica como revela a afirmativa de Laura: "[...] como en vou explicar o que eu vejo para que a pessoa que está longe entenda claramente o que estou vendo?" A professora instigou os 
alunos a pensarem maneiras de amenizar a subjetividade no registro e os alunos revelaram que uma forma seria a utilização de vocabulário mais técnico partilhado pelos membros de uma área de pesquisa. Latour e Wolgar (1997) apontam para o fato de que o registro da observação, chamados por eles de "inscrições", se desenvolve desde rabiscos idiossincráticos iniciais feitos pelo pesquisador até o uso de descrições de fenômenos no âmbito do conhecimento consensual científico de uma determinada área. Em suma, ter uma linguagem comum é algo essencial para a comunicação científica com os pares. A intuição da aluna parece apontar para a necessidade desse processo de normalização para que a comunicação científica se dê de forma eficiente. Em sua orientação pedagógica, a professora foi capaz de valer-se da pergunta da discente e conduzir a turma para esse entendimento.

Nesse mesmo encontro transcorreu outra atividade de microscopia, com observação de cortes histológicos de fígado de mamífero, cujo objetivo foi refinar a diferença entre a observação e o registro da observação. Quando a professora questionou a ausência de alguns componentes celulares nos desenhos feitos pelos licenciandos, Dayane afirmou: "eu não desenhei porque achei que essas bolinhas não fossem importantes". A partir da fala da aluna, a professora arguiu os outros participantes sobre se seus registros evidenciavam ou não suas observações, indo ao encontro de outros trabalhos relacionados ao ensino dessas habilidades, isto é, atuando de forma atenta durante o processo e introduzindo questionamentos incentivadores à reflexão (DRIVER, 1985; KLENTSCHY, 2010). Diante da argumentação docente, os alunos admitiram que faltavam estruturas em seus registros. Mesmo com pré-requisitos citológicos adquiridos em outras disciplinas da grade curricular, devem-se relembrar os já citados preceitos defendidos por Fleck (1986a, 1986b, 2010) sobre o "observador treinado": a habilidade de observar cientificamente requer treinamento e experiência na área de conhecimento, com a boa observação sendo dependente necessariamente do domínio do observador numa determinada área científica. Inclusive, os estudantes elencaram em suas anotações estruturas celulares que não foram visualizadas na observação ao microscópio de luz, tais como a membrana plasmática e outras organelas além do núcleo.

Driver (1985) ressalta que as observações científicas dos alunos baseiam-se em conhecimentos prévios e expectativas. O professor, neste processo, deve auxiliar na reflexão dos alunos acerca dos dados coletados, incentivando a repetição e a verificação, por meio da comparação entre os discentes, até que o que "não se via", apareça aos olhos do observador. De acordo com Klentschy (2010), a orientação também deve estimular a elaboração de um registro mais fidedigno à observação do aluno, e não o que esse aluno pensa que é o esperado pelo professor observar. Nesse processo, Smith e Reiser (2005) afirmam que a atuação do professor precisa encontrar um equilíbrio para que os alunos protagonizem suas atividades observacionais e não somente obedeçam instruções, caso haja excesso de orientação. Esse fato foi registrado, por exemplo, nas pesquisas de Haslam e Gunstone $(1996,1998)$ com alunos de ensino médio da Austrália que se desinteressam por determinadas atividades nas aulas de ciências porque já sabiam os resultados, previamente anunciados pelos professores.

Após todas as aulas, os alunos foram entrevistados no intuito de coletar dados acerca das suas percepções sobre a observação e o registro da observação. O aluno Rian expôs: "pra mim ficou claro que os procedimentos são as estruturas que sustentam o conbecimento cientifico." No que concerne à observação, ele comentou: 
[antes das aulas] eu não tinha pensado, não tinha parado pra refletir, sobre a subjetividade da observação, sobre o foco da observação que é importante. [...] Acreditava que a observação só dependia do objeto a ser observado e não do indivíduo que o observa. [...] Penso que compreender melhor sobre os aspectos que envolvem a observaşão auxilia no aprendizado, porque demonstraria pra mim mesmo que o que está escrito lá no livro podem ser inferências sobre algumas observações de algum cientista.

Sobre o registro da observação, Rian disse: "o registro realmente reflete a observação, por isso que ele também é subjetivo. [...] [Penso que] também o registro era coisa, pra mim antes, também automática, assim como observar."

Em relação aos procedimentos e habilidades da observação e registro da observação, Isaura comentou: "saber o que observar muda o nosso jeito de entender as coisas... cada um vê de um jeito... cada um com a sua experiência... muita coisa eu não sabia em relação a observar, porque muitas vezes a gente é preguiçoso [ao observar]."

Quanto ao registro, Isaura destacou: "eu aprendi a importância do registro... porque a gente às vezes só olha, observa... ah [aponta para o fio] esse fio ali é amarelo... mas no registro você descreve o que você está observando... e no descrever você ganha informações sobre o objeto da observação...".

Quanto à observação, três alunos (Rian, Isadora e Isaura) perceberam e enfatizaram o caráter subjetivo. Duas alunas (Dayane e Laura) destacaram a necessidade de observar detalhadamente o objeto. Quanto ao registro da observação, dois alunos (Rian e Gisela) enfatizaram a subjetividade e uma aluna (Laura) aponta para a necessidade do detalhamento no registro.

No que concerne ao caráter subjetivo da observação e do registro da observação apontados pelos alunos, tal perspectiva é acentuada nos trabalhos de Fleck (1986a, 1986b, 2010) quando discorre a respeito da formação técnica de quem observa, implicando na inevitabilidade da aquisição de conhecimentos técnicos para que o observador especialista se destaque do leigo. Além desses conhecimentos técnicos, Driver (1985) acentua que a observação é um processo dinâmico por meio do qual o observador contrasta suas percepções com suas expectativas, sendo o registro um indicativo de sua compreensão em relação a um fenômeno e, acrescentamos, ao objeto observado. Também devem ser consideradas as variações dos órgãos dos sentidos entre distintos observadores e ao longo dos ciclos vitais desses indivíduos (STANSFIELD, 2012).

Sobre a necessidade de observar e registrar detalhadamente poder-se-ia inferir que as atividades de microscopia influenciaram nessa tomada de conhecimento por parte dos discentes e que, se outras atividades tivessem sido realizadas como substitutivas das de microscopia (por exemplo, a observação e o registro do comportamento de distintas espécies de peixes em um aquário), talvez os alunos não tivessem percebido a citada "necessidade de detalhar". Porém, os trabalhos relacionados com a concepção de roteiros didáticos de procedimentos como a observação e o registro apresentam, em comum, questões direcionadas que estimulam a execução de registros detalhados a partir de observações cuidadosas. O grau de detalhamento da observação e do registro está relacionado, entre outros aspectos, com a qualidade das perguntas elaboradas e a atuação do professor ao longo do processo de ensino, incentivando sistematicamente a reflexão por parte do discente. A incitação à observação e aos registros minuciosos é explícita nos trabalhos de Anderson, Martin e Faszewski (2006), Checkovich e Sterling (2001) e Ramón y Cajal (2005). 
Cabe salientar a atuação da professora como fundamental para proporcionar o desenvolvimento da percepção do contraste entre o que foi visto ao microscópio, o objeto observado, e o que foi desenhado, isto é, o registro da observação. Ressalta-se que aulas com uso de microscópio de luz não garantem necessariamente essa apropriação discente, pois podem se reduzir à mera visualização de um espécimen sem explorar, por meio de protocolos didáticos bem elaborados, a rica atividade investigativa possível de ocorrer a partir do manuseio desse instrumental. As famosas filas de alunos formadas em laboratórios de Biologia por falta de número suficiente de aparelhos ópticos nas escolas (LORETO; SEPEL, 2003), em geral, não contribuem para a percepção por parte dos alunos de que a observação (feita de maneira célere) e o registro da observação (normalmente não incluído na atividade) são habilidades da investigação científica em Biologia Celular e Molecular que exigem detalhamento.

Nesta pesquisa, após a aplicação de todas as atividades da unidade didática, concluímos que os alunos refinaram suas percepções sobre a observação e o registro da observação da investigação científica, passando a distingui-las e considerá-las como dependentes do observador, caracterizando-as como subjetivas, detalhadas, influenciadas pelos conhecimentos prévios e técnicos de quem observa e registra, e sofrendo a interferência do instrumental. Acentuamos o papel orientador fundamental do professor ao longo da aplicação de qualquer unidade didática que inclua o ensino de habilidades e procedimentos da investigação científica. Porém, reflete-se que não devem ocorrer exageros nessa orientação para que haja maior possibilidade de reflexão pelos alunos ao longo do processo investigativo e que esses sejam efetivamente os protagonistas das atividades aplicadas.

O ensino e o registro da observação são objetivos educacionais relevantes na educação dos licenciandos de Ciências Biológicas. Ressaltamos que esse ensino deve ser fundamentado em uma visão epistemológica que reflita a natureza da Ciência e em uma pedagogia que proporcione a reflexão sobre os mesmos. Dessa forma, esperamos que os licenciandos tornemse capacitados para ações pedagógicas adequadas e frutíferas quando no futuro tornarem-se professores na educação básica.

\section{Referências}

AHTEE, M. et al. Primary school student teachers' views about making observations.

NorDiNa: nordic studies in science education, Oslo, v. 5, n. 2, p. 218-141, 2009. Disponível em: <https://www.journals.uio.no/index.php/nordina/article/view/346/380>. Acesso em: 4 out. 2016.

AMERICAN ASSOCIATION FOR THE ADVANCEMENT OF SCIENCE. Science: a process approach. Washington, 1965.

ANDERSON, K. L.; MARTIN, D. M.; FASZEWSKI, E. E. Unlocking the power of observation. Science and Children, Arlington, v. 44, n. 1, p. 32-35, 2006. 
Carmo, K. V.; Ferreira, L. B. M.; Medeiros y Araujo, C.

ASHBROOK, P. Developing observation skills. Science and Children, Arlington, v. 48, n. 2, p. 22-24, 2010.

BOGDAN, R.; BIKLEN, S. Investigação qualitativa em educação. Porto: Porto Editora, 1994.

BRASIL. Conselho Nacional de Saúde. Resolução 196/96. Diretrizes e normas regulamentadoras de pesquisas envolvendo seres humanos. Brasília, 1996.

CARMO, K. V. Habilidades e procedimentos da investigação científica: percepções de um grupo licenciandos em ciências biológicas a partir de uma sequência didática em biologia celular e molecular. 2012.124 f. Dissertação (Mestrado Profissional em Ensino de Ciências)

- Universidade de Brasília, Brasília, 2012.

CHECKOVICH, B. H.; STERLING, D. R. Oh say can you see. Science and Children, Arlington, v. 38, n. 4, p. 32-35, 2001.

COIL, D. et al. Teaching the process of science: faculty perceptions and an effective methodology. CBE: life sciences education, Bethesda, v. 9, n. 4, p. 524-535, 2010. Disponível em: < https://www.ncbi.nlm.nih.gov/pmc/articles/PMC2995770/pdf/cbe524.pdf>. Acesso em: 4 out. 2016.

DASTON, L. On scientific observation. Isis, Chicago, v. 99, n. 1, p. 97-110, 2008.

DASTON, L.; LUNBECK, E. Histories of scientific observation. Chicago: University of Chicago Press, 2011.

DESSEN, E. M. B.; OYAKAWA, J. (Org.). Microscopia. São Paulo: Centro de Estudos do Genoma Humano, [2011]. Disponível em: <http://genoma.ib.usp.br/sites/default/files/ protocolos-de-aulas-praticas/microscopia_2.pdf>. Acesso em: 13 out. 2015.

DRIVER, R. The pupil as scientist? Milton Keynes: Open University Press, 1985.

FLECK, L. Gênese e desenvolvimento de um fato científico. Belo Horizonte: Fabrefactum, 2010.

Scientific observation and perception in general. In: COHEN, R. S.; SCHNELLE, T. (Org.). Cognition and fact. Dordrecht: Reidel, 1986a. p. 59-78.

. To look, to see, to know. In: COHEN, R. S.; SCHNELLE, T. (Org.). Cognition and fact. Dordrecht: Reidel, 1986b. p. 129-151.

GIL PÉREZ, D. et al. Para uma imagem não deformada do trabalho científico. Ciência \& Educação, Bauru, v. 7, n. 2, p. 125-153, 2001. Disponível em: < http://dx.doi.org/10.1590/ S1516-73132001000200001>. Acesso em: 4 out. 2016.

GOSTEV, M.; WEISS, F. M. Firsthand nature: a classroom environment that encourages direct observation of nature helps develop young students' scientific literacy. Science and Children, Arlington, v. 44, n. 8, p. 48-51, 2007.

HANSON, N. R. Observação e interpretação. In: MORGENBESSER, S. (Org.). Filosofia da ciência. São Paulo: Cultrix, 1975. p. 127-138. 
Percepções de um grupo de licenciandos em Ciências Biológicas ...

HANSON, N. R. Patterns of discovery: an inquiry into the conceptual foundations of science. Cambridge: Cambridge University Press, 1965.

HANUSCIN, D. L.; ROGERS, M. A. P. Learning to observe and infer. Science and Children, Arlington, v. 45, n. 6, p. 56-57, 2008.

HARLEN, W. Purposes and procedures for assessing science process skills. Assessment in Education: principles, policy \& practice, Abingdon, v. 6, n. 1, p. 129-144, 1999.

. Teaching, learning and assessing science 5-12. London: Paul Chapman, 2002.

HASLAM, F.; GUNSTONE, R. The influence of teachers on student observation in science classes. In: ANNUAL MEETING OF THE NATIONAL ASSOCIATION FOR RESEARCH IN SCIENCE TEACHING, 71., 1998, San Diego. Disponível em: < http:/ / files.eric.ed.gov/fulltext/ED446927.pdf >. Acesso em: 13 out. 2015.

Observation in science classes: students' beliefs about its nature and purpose. In: ANNUAL MEETING OF THE NATIONAL ASSOCIATION FOR RESEARCH IN SCIENCE TEACHING, 69., 1996, St. Louis. Disponível em: < http://files.eric.ed.gov/ fulltext/ED396909.pdf >. Acesso em: 13 out. 2015.

HAURY, D. L. Fundamental skills in science: observation. Columbus: ERIC

Clearinghouse for Science Mathematics and Environmental Education, 2002. Disponível em: <http://www.ericdigests.org/2004-1/skills.htm>. Acesso em: 30 set. 2015.

HOLMES, F. L.; RENN, J.; RHEINBERGER, H. Reworking the bench: research notebooks in the history of science. Dordrecht: Kluwer, 2003.

KLENTSCHY, M. P. Using science notebooks in middle school. Arlington: NSTA Press, 2010.

KUHN, T. A estrutura das revoluções científicas. 5. ed. São Paulo: Perspectiva, 1998.

LATOUR, B.; WOOLGAR, S. A vida de laboratório: a produção dos fatos científicos. Rio de Janeiro: Relume Dumará, 1997.

LAWSON, A. Basic inferences of scientific reasoning, argumentation, and discovery.

Science \& Education, Dordrecht, v. 94, n. 2, p. 336-364, 2009.

LORETO, E. L. S.; SEPEL, L. M. N. Atividades experimentais e didáticas de biologia molecular e celular. 2. ed. São Paulo: Sociedade Brasileira de Genética, 2003.

MESSAGE, D. et al. Práticas de citologia (morfologia e fisiologia). Viçosa: Universidade Federal de Viçosa, 1988.

NORRIS, S. Defining observational competence. Science Education, Hoboken, v. 68. n. 2, p. 129-142, 1984.

OĞUZ- ÜNVER, A.; YÜRÜMEZOĞLU, K. A teaching strategy for developing the power of observation in science education. Ondokuz Mayis University of Education Journal, Samsun, v. 28, p. 105-119, 2009. Disponível em: <http://www.acarindex.com/dosyalar/ makale/acarindex-1423910354.pdf>. Acesso em: 4 out. 2016. 
Carmo, K. V.; Ferreira, L. B. M.; Medeiros y Araujo, C.

PADILLA, M. J. The science process skills. Research Matters - to the Science Teacher, Reston, n. 9004, 1990. Disponível em: < https://www.narst.org/publications/research/skill. cfm>. Acesso em: 13 out. 2015.

PATTON, M. Q. Qualitative research \& evaluation methods. 3. ed. Thousand Oaks: Sage, 2002.

RAMON y CAJAL, S. Reglas y consejos sobre investigación científica: los tónicos de la voluntad. 3. ed. Madrid: Consejo Superior de Investigaciones Científicas, 2005.

SMITH, B. K.; REISER, B. J. Explaining behavior through observational investigation and theory articulation. The Journal of the Learning Sciences, Philadelphia, v. 14, n. 3, p. 315-360, 2005.

STANSFIELD, W. D. Science \& the senses: perceptions and deceptions. The American Biology Teacher, Oakland, v. 74, n. 3, p. 145-149, 2012.

Artigo recebido em 15/10/2015. Aceito em 21/04/2016.

Endereço para contato: Universidade Federal de Goiás (UFG), Departamento de Ciências Biológicas, Regional Catalão, Av. Dr. Lamartine Pinto de Avelar, 1120, St. Universitário, CEP 75704-020, Catalão, GO, Brasil. 